Article

\title{
Evaluation of Two Different Flooring Designs for Rabbit Housing in Accordance with German Welfare Regulations: Soiling and Mortality
}

\author{
Sally L. Rauterberg *, Joana Bill, Sarah Kimm, Nicole Kemper® and Michaela Fels@ \\ Institute for Animal Hygiene, Animal Welfare and Farm Animal Behavior, University of Veterinary Medicine \\ Hannover, Foundation, Bischofsholer Damm 15, D-30173 Hannover, Germany; \\ joana.bill@tiho-hannover.de (J.B.); sarah.kimm@tiho-hannover.de (S.K.); nicole.kemper@tiho-hannover.de (N.K.); \\ michaela.fels@tiho-hannover.de (M.F.) \\ * Correspondence: sally.rauterberg@tiho-hannover.de; Tel.: +49-511-856-8966
}

Received: 7 November 2019; Accepted: 2 December 2019; Published: 4 December 2019

\begin{abstract}
The aim of the present study was to investigate a new housing system for fattening rabbits with two different flooring designs (F1 and F2) in accordance with new legal requirements in Germany (11 $\mathrm{mm}$ slats and $11 \mathrm{~mm}$ gaps, elevated platform with $15 \%$ perforation), in comparison with an established system with wire mesh flooring $(C)$. While F1 flooring was made of punched slatted plastic panels, F2 consisted of fixed single rods with a rounded surface. In six batches with F1 and C housing, and subsequently three batches with F2 housing, soiling of rabbits' hind feet, pens, and cages as well as mortality rates were recorded. While pens and rabbits in F2 conditions were assessed as being cleaner than $\mathrm{F} 1$, neither reached the cleanliness of $\mathrm{C}$ rabbits and cages. Mortality was highest in F1 housing $(18.1 \%)$ and comparable between F2 (10.3\%) and C housing $(11.7 \%)$. The present investigations showed different results in terms of soiling and mortality for different implementations of the German regulations. Nevertheless, both floors in accordance with these requirements revealed hygienic disadvantages compared to the established cages. Further research is necessary in order to keep rabbits under good hygienic conditions and in compliance with legal requirements.
\end{abstract}

Keywords: fattening rabbits; legal requirements; floor type; slatted plastic floor; plastic net floor; wire net floor; wire mesh floor; elevated platform

\section{Introduction}

In Europe, commercially kept rabbits are usually housed in cages with wire mesh flooring [1]. Even if this floor type is preferred in fattening rabbits at higher temperatures [2], is easy to keep clean and dry, and is generally rated as the most hygienic option [3,4], it also seems to have some disadvantages. Thus, wire mesh flooring is questionable in its comfortability. This was shown in free choice tests, where wire mesh was less preferred compared to plastic floors, especially by younger rabbits $[2,5,6]$ and at lower temperatures [2]. Also, rabbit does used elevated platforms made of wire mesh less frequently than platforms made of plastic mesh, leading to the conclusion that wire mesh may be less comfortable for the animals [7]. Wire mesh flooring may also restrict rabbits' movement behavior, as the movement patterns can be impaired, especially in young rabbits [8]. In rabbit does, which are usually kept for longer periods, footpads can become stressed and injuries may occur frequently on wire mesh floors $[3,9,10]$. As solid and straw-littered floorings may bring some disadvantages due to hygienic challenges and may have additional negative effects on the performance of rabbits [5,11-13], their practical application is limited in commercial rabbit husbandry. Thus, alternatives such as perforated plastic flooring seem to be promising, and should be developed further and assessed in practice. 
Moreover, fattening rabbits were already observed to prefer slatted plastic flooring [2,6,14], but avoid solid flooring and straw deep litter compared to wire mesh flooring $[5,11,15]$. Nevertheless, when developing alternative floor types in commercial rabbit husbandry, the advantages of wire flooring should be kept. Thus, the used floor has to prevent rabbits' contamination and be easy to clean and disinfect. An accumulation of moisture and droppings has to be prevented $[3,9,16]$. Moreover, the preference of rabbits for less-perforated floor types decreases with increased soiling [5,17]. However, in addition to solid flooring and deep straw litter [5,11-13], some types of perforated plastic flooring were observed to negatively affect the hygienic conditions, depending on the degree of perforation, shape, and structure $[9,18,19]$.

Nevertheless, welfare concerns regarding conventionally used wire mesh cages led to recent changes in the legal requirements in different European countries [1]. Therefore, the development and assessment of new suitable housing systems with alternative floor types is urgently required. This also applies to Germany, as minimum requirements for keeping rabbits were added to the Animal Welfare Act in 2014 [20]. This regulation includes, among other specifications, special requirements for the floor design. Accordingly, the maximum gap and hole widths for fattening rabbits must not exceed $11 \mathrm{~mm}$ and the minimum slat widths have to correspond to this. In addition, an elevated platform with a maximum degree of perforation of $15 \%$ has to be provided. However, previous investigations indicated the negative effects of this floor design on the hygienic conditions $[18,21,22]$. Due to the fact that the new regulations have to be implemented on all German rabbit farms as of 2019, the aim of the present study was to investigate two different types of plastic flooring meeting the German legal requirements. As the soiling of a floor seems to be a crucial factor influencing animal health and welfare, and thus is important for evaluating new floors [19], soiling was evaluated in detail for the new slatted plastic floors. Additionally, data on the development of pododermatitis as well as the rabbits' mortality were collected, and all data were compared to those of cages and rabbits from an established cage system equipped with a wire mesh floor on the same farm.

\section{Materials and Methods}

\subsection{Animals and Housing}

The study was carried out on a commercial German rabbit farm keeping about 600 rabbit does (Hyplus PS 19) and their offspring (Hyplus PS $19 \times$ PS 59, Hypharm S.A.S., France). In the present investigations, growing rabbits were kept in six batches under F1 housing conditions ( $\mathrm{N}=1422$ rabbits), and afterwards in three batches under $\mathrm{F} 2$ conditions ( $\mathrm{N}=666$ rabbits). Additionally, control groups $(\mathrm{C})$ were kept in six batches ( $\mathrm{N}=1056$ rabbits) in an established conventional cage system on the same farm. On this farm, rabbit does were vaccinated against rabbit hemorrhagic disease (RHD), enteritis, and Pasteurella multocida, while fattening rabbits were not vaccinated. The present study was approved by the Animal Welfare Office of the University of Veterinary Medicine, Hannover, Germany.

F1 and F2 rabbits were kept in the same housing system; for F2 rabbits, however, the floor design was modified. The housing system consisted of 24 single units for housing 24 does and their litters. Each single unit measured $80 \mathrm{~cm}$ (length) $\times 80 \mathrm{~cm}$ (width), with an open top and walls made of wire mesh. Each unit also provided a box (the former nest box) with a roof of slatted plastic flooring $(30 \mathrm{~cm} \times 40 \mathrm{~cm} \times 27 \mathrm{~cm}$ (height)), an additional floor space next to the box $(30 \mathrm{~cm} \times 40 \mathrm{~cm}$ without roof), an elevated platform, and environmental enrichment, such as a plastic tube and gnawing materials (wood chain, a wood holder, a chain with plastic elements, and a cotton rope). After rearing in litters within the single units, kits were weaned at the age of 31 days by removing the does. Subsequently, large groups of young rabbits were formed, mixing up to six litters by opening the doors between six adjacent units, creating a large pen $\left(58 \pm 7\right.$ rabbits per group, maximum 13 rabbits $/ \mathrm{m}^{2}$ ground area without an elevated platform). Rabbits remained in these groups for the entire fattening period until their 78th day of life. Water was available ad libitum from two nipple drinkers per (former) single unit, as well as a commercial pelleted diet and chopped hay. Housing was equipped with a negative 
pressure ventilation system and manure was removed daily by means of a manure belt. Artificial lighting lasted from 06:00 to 19:00, with dawn from 06:00 to 06:30 and dusk from 18:30 to 19:00. Average temperature and relative humidity were $17.9 \pm 7{ }^{\circ} \mathrm{C}$ and $65.2 \pm 10.1 \%$ for $\mathrm{F} 1$ housing and $17.5 \pm 4.1^{\circ} \mathrm{C}$ and $68.4 \pm 5.1 \%$ for F2 housing.

F1 housing conditions were characterized by a floor and an elevated platform $(60 \mathrm{~cm} \times 55 \mathrm{~cm} \times 37 \mathrm{~cm}$ (length $\times$ width $\times$ heightin which it is attached to the wall)) made of punched slatted plastic panels with $11 \mathrm{~mm}$ slats and $11 \mathrm{~mm}$ gaps (Figure 1a). In order to achieve a 15\% perforation of the elevated platform, it was covered for the most part with a flat, solid plastic plate $(42 \mathrm{~cm} \times 55 \mathrm{~cm}$, Figure 2a).

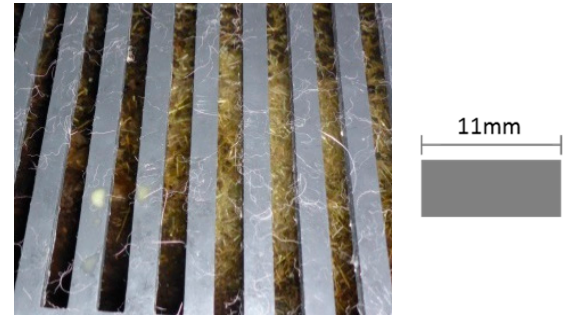

(a)

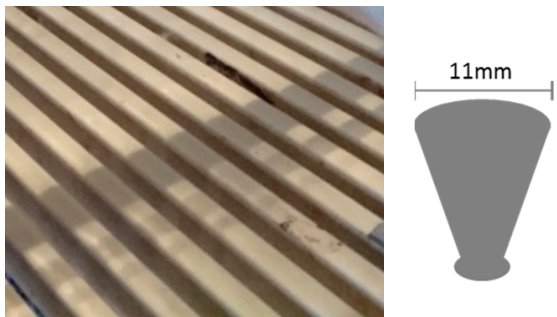

(b)

Figure 1. F1 (a) and F2 flooring designs (b) with schematic figure of the cross-section.

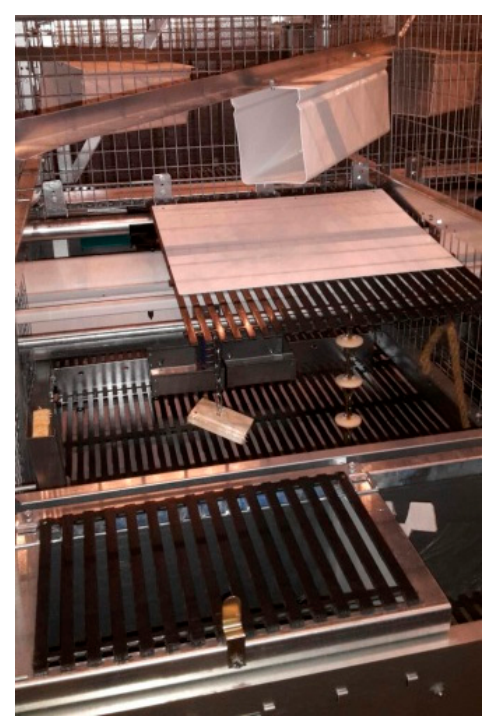

(a)

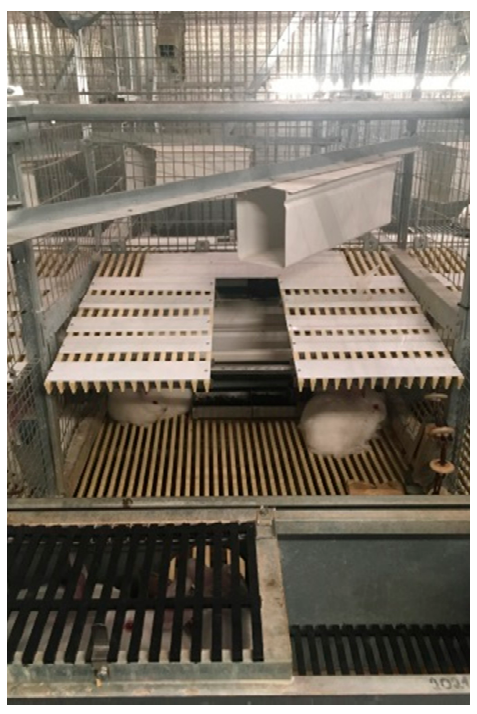

(b)

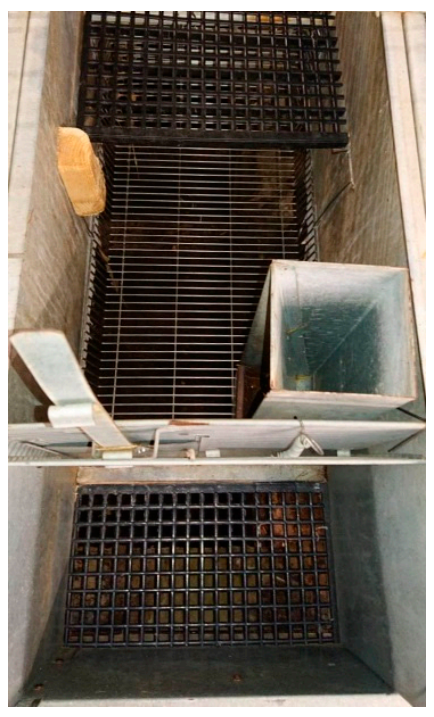

(c)

Figure 2. F1 (a), F2 (b), and C housing conditions (c).

F2 housing conditions offered a floor and platform (divided into two areas of $60 \mathrm{~cm} \times 30 \mathrm{~cm} \times 37 \mathrm{~cm}$, respectively), with slats consisting of $11 \mathrm{~mm}$ rods with a rounded surface (Figure $1 \mathrm{~b}$ ), which were fastened at a distance of $11 \mathrm{~mm}$ from each other onto a bracket. To achieve a $15 \%$ perforation on the elevated platform, narrow strips of plastic sheeting $(6 \mathrm{~cm} \times 30 \mathrm{~cm})$ were fixed onto it at a distance of $3 \mathrm{~cm}$. In addition, one plastic sheet was fixed at the back of the platforms to prevent soiling of the feeders from above, this again covering $18 \mathrm{~cm} \times 20 \mathrm{~cm}$ of each platform (Figure 2b).

Both F1 and F2 rabbits were kept under the respective housing conditions from birth, as the mothers were also kept in the system until weaning. Before starting a new batch (when new pregnant does entered the system), the system was cleaned and disinfected. Thus, each batch of F1 and F2 does (later giving birth to the fattening rabbits) started with cleaned floors.

$C$ rabbits had been born in conventional wire mesh cages $(70 \mathrm{~cm} \times 50 \mathrm{~cm} \times 30 \mathrm{~cm})$ with a nest box $(30 \mathrm{~cm} \times 28 \mathrm{~cm} \times 28 \mathrm{~cm})$ on the same farm, and were moved to other wire cages after weaning at the 
age of 31 days. There, groups of eight rabbits, composed of four rabbits from two litters each, were kept in a total of 22 cages $(70 \mathrm{~cm} \times 35 \mathrm{~cm} \times 52 \mathrm{~cm})$ with wire mesh flooring $(12 \times 96 \mathrm{~mm}$ holes and $3 \mathrm{~mm}$ wire diameter), an elevated platform $(32 \mathrm{~cm} \times 39 \mathrm{~cm} \times 27 \mathrm{~cm})$, a box $(25 \mathrm{~cm} \times 39 \mathrm{~cm} \times 24 \mathrm{~cm}$ wire mesh roof), and one gnawing stick ( 23 rabbits $/ \mathrm{m}^{2}$ ground area without an elevated platform). The elevated platform and box had a slatted plastic floor $(16 \times 16 \mathrm{~mm}$ holes and $7 \mathrm{~mm}$ slats, Figure $2 \mathrm{c})$. Water from one nipple drinker per cage as well as a commercial pelleted diet and chopped hay were available ad libitum. Housing provided a negative pressure ventilation system. Manure was stored in concrete pits below the cages, which were emptied after each batch, meaning each batch started with a cleaned and disinfected housing system. In $C$ housing, artificial lighting during the daytime lasted from 07:00 to 19:00, the average temperature was $15.2 \pm 5.5^{\circ} \mathrm{C}$, and relative humidity $68.4 \pm 11.7 \%$. This housing system was established on the farm for many years.

\subsection{Data Collection}

\subsubsection{Soiling and Pododermatitis}

All 24 units and 22 cages were investigated for soiling in the middle (52 days of age) and at the end of a fattening period (77 days of age) using the four-stage scoring system used by Rauterberg et al. (Table 1) [21]. Scoring was conducted separately for the floor space and the elevated platform. Over the same days, soiling of hind feet from a sample of rabbits from F1 ( $\mathrm{N}=283$ rabbits), $\mathrm{F} 2(\mathrm{~N}=175$ rabbits), and $\mathrm{C}(\mathrm{N}=269$ rabbits) housing conditions was determined using the same scoring system (Table 1, Figure 3). Right and left feet were assessed separately, and subsequently the maximum score was assigned to the respective individual. At the same time, the same feet were evaluated for the development of pododermatitis on a scale from 0 to 2 as follows: score 0 (skin and fur intact), score 1 (loss of hair), score 2 (callus formation).

Table 1. Scoring system to evaluate the soiling of floor spaces, platforms, and feet [21].

\begin{tabular}{cc}
\hline Score & Soiling \\
\hline 0 & Clean and dry \\
1 & Dry soiled $\leq 50 \%$ of total area \\
2 & Dry soiled $>50 \%$ of total area \\
3 & Wet soiled \\
\hline
\end{tabular}

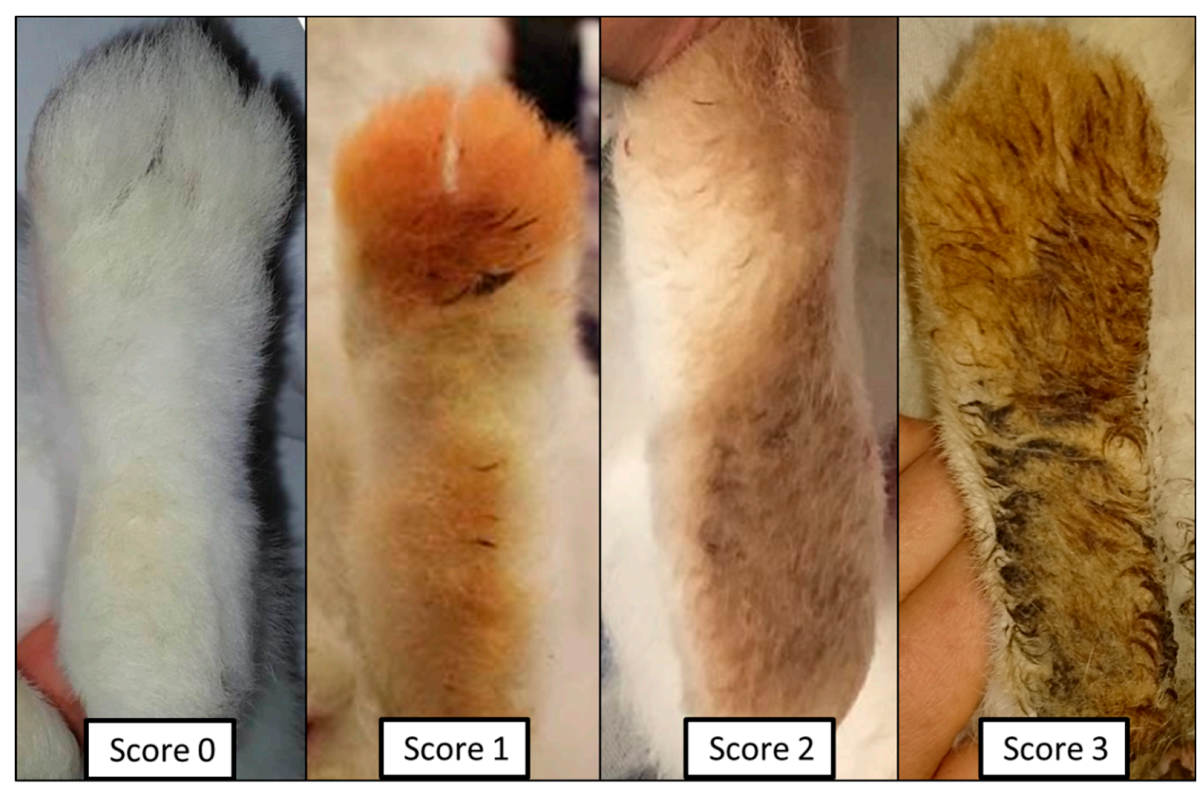

Figure 3. Scoring system for soiling of rabbit's hind feet ranging from $0-3$, according to Table 1 . 


\subsubsection{Mortality Rates}

Mortality rates were calculated from weaning to slaughter by counting the total number of rabbits in all pens and cages of the respective housing system at weaning (day 31, i.e., at the start of the fattening period), and at the end of the fattening period (day 77). Subsequently, the percentage of animal losses was calculated for each batch in each housing system (F1, F2, and C).

\subsection{Statistical Analysis}

Statistical analysis was performed using R 3.6.1 [23]. Level of significance was set at $p<0.05$. Soiling of the different areas in units and cages and of the hind feet was analyzed using an ordered logistic regression model with the housing system, observation day, and batch as fixed effects, using the $\mathrm{R}$ packages MASS (Support Functions and Datasets for Venables and Ripley's MASS) [24], lmtest (Testing Linear Regression Models) [25], and AER (Applied Econometrics with R) [26]. To analyze overall differences in the mortality rates between the housing systems, the Kruskal-Wallis test was performed.

\section{Results}

\subsection{Soiling}

\subsubsection{Floor Space}

As shown in Figure 4, almost 70\% of the floor space in F1 housing was assessed as soiling score 3 at both observation days, while score 0 was never observed. In F2, about $3 \%$ of floor space was assessed as score 0 , while most commonly score 1 was assigned. $C$ floor space was mostly assessed as score 1 and 0 . Soiling differed between $\mathrm{F} 1$ and $\mathrm{C}$ housing $(p<0.001)$, with $\mathrm{C}$ being cleaner than $\mathrm{F} 1$, but with no effect of observation day $(p>0.05$, Figure 4$)$. F1 and F2 housing also differed significantly $(p<0.001)$, with F2 housing being cleaner than F1, but with no effect of observation day $(p>0.05)$. F2 and C housing again differed significantly $(p<0.001)$, with $C$ housing being cleaner than $F 2$, again with no effect of observation day $(p>0.05)$. The batch affected floor soiling in F1 and C housing $(p<0.05)$.

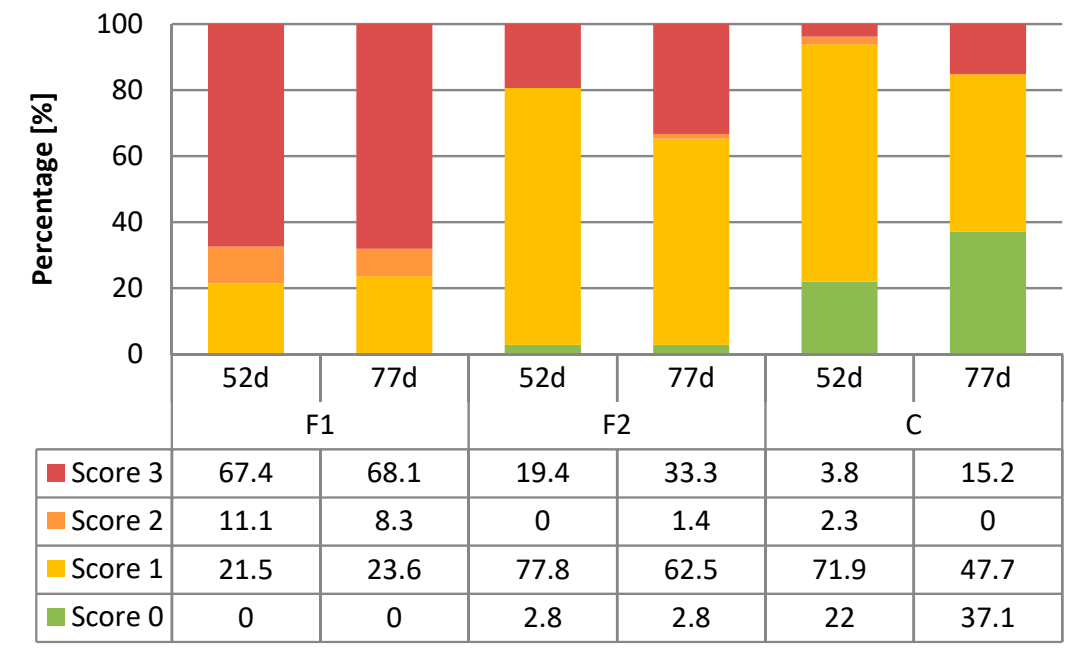

Figure 4. Distribution (\%) of soiling scores 0-3 assessed for the floor space in F1, F2, and C housing at 52 and 77 days of age $(\mathrm{d})$.

\subsubsection{Elevated Platform}

In F1 housing, score 1 was assigned to most elevated platforms. In F2 housing, 43\% of the elevated platforms were given soiling score 0 at day 52 . In contrast, at day 77 , only $1 \%$ of platforms were assessed as score 0 and $15 \%$ as score 3 , whereas score 1 was assigned most frequently $(80 \%)$. Soiling of platforms in F2 was affected by the observation day $(p<0.001)$, with significantly higher soiling at day 
77 than at day 52. $C$ platforms were solely assessed as score 0 and score 1 at both observation days (Figure 5). F1 housing differed significantly to $C$ housing $(p<0.001)$, with $C$ being cleaner than $F 1$, but with no effect of the observation day $(p>0.05)$. Soiling of F1 and F2 platforms also differed significantly $(p<0.001)$, but with an effect of the observation day $(p<0.001)$. When evaluating the observation days separately, F1 and F2 only differed significantly at day $52(p<0.001)$, with F2 being cleaner than F1. F2 and $C$ platforms again differed significantly at both observation days $(p<0.001)$, with $C$ being cleaner than F2. An effect of batch on platform soiling was observed in F1 housing $(p<0.01)$.

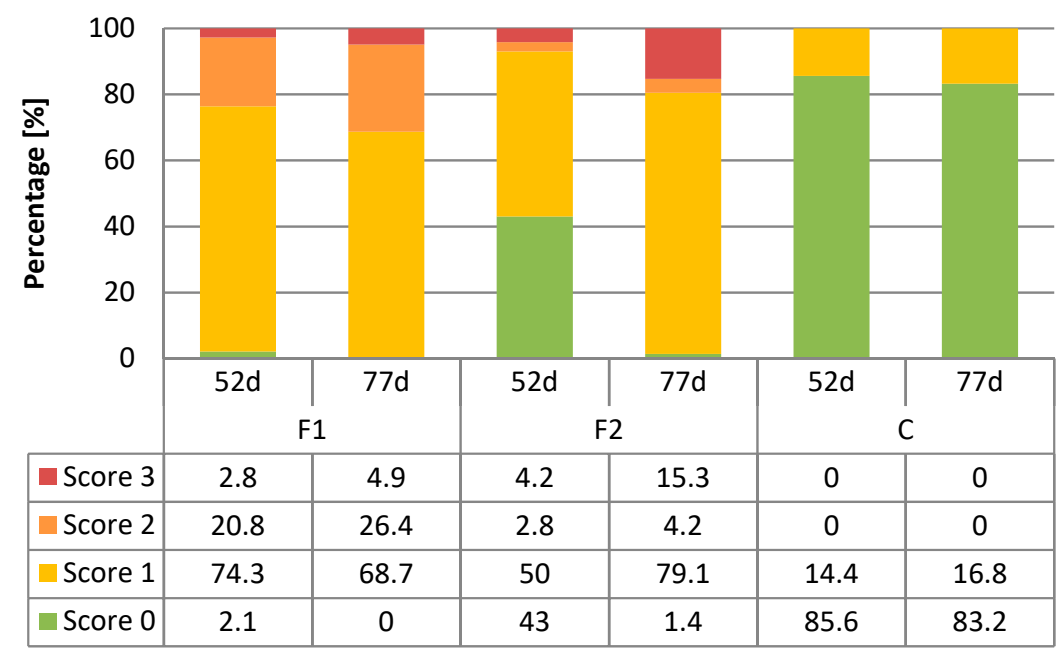

Figure 5. Distribution (\%) of soiling scores 0-3 assessed for elevated platforms in F1, F2, and C housing at 52 and 77 days of age $(\mathrm{d})$.

\subsubsection{Feet}

Soiling of rabbits' hind feet in F1 housing differed between day 52 and day $77(p<0.01)$, with more feet assessed as score 3 on day 77. In F2 housing, hind feet were mostly assessed as score 1, with no effect of observation day. At day 52 , rabbits from $C$ housing were mostly assessed as score 1 , followed by score 0 . Soiling in C housing differed significantly between day 52 and day $77(p<0.001)$, with more feet assessed as score 0 at day 77 (Figure 6). At both observation days, soiling of feet of F2 and F1 rabbits differed significantly $(p<0.001)$, with F2 feet being cleaner than F1. Also, soiling of feet of F1 and C $(p<0.001)$ and F2 and C rabbits differed significantly at both observation days $(p<0.01)$, with $C$ feet being cleaner. Batch had a significant effect for $F 2$ and $C$ housing $(p<0.001)$.

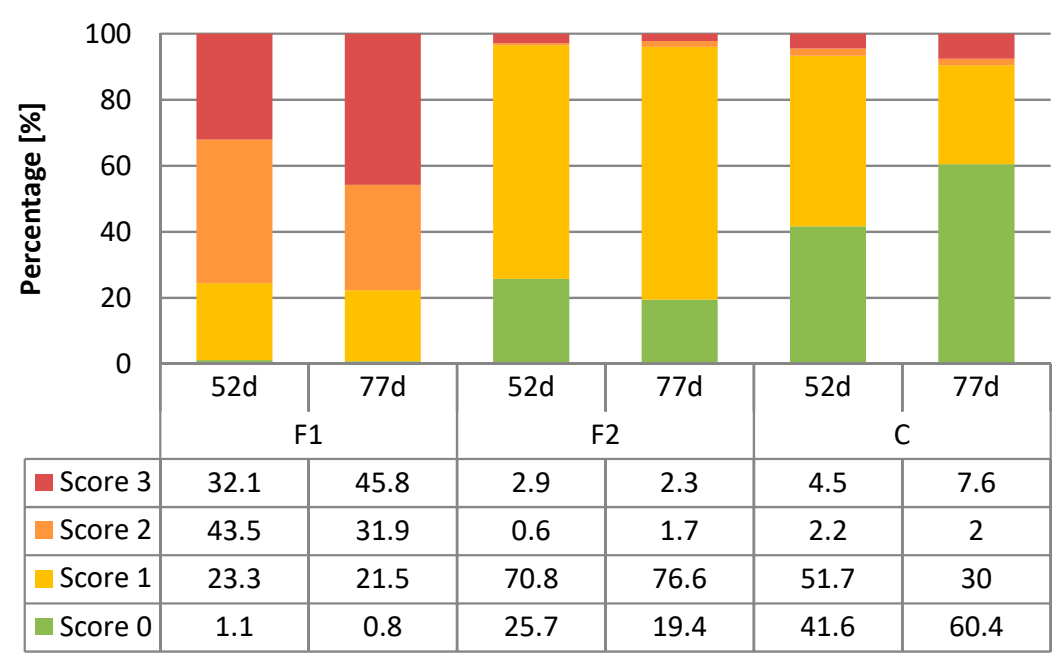

Figure 6. Distribution (\%) of soiling scores 0-3 assessed for feet of rabbits in F1, F2, and C housing at 52 and 77 days of age $(d)$. 


\subsection{Pododermatitis}

All rabbits from F1, F2, and C housing were assessed as score 1 at both observation times. Thus, all of them showed a small hairless area at the back of their hind feet, independently of the housing system (Figure 7). However, pododermatitis (score 2) was absent in the present study.

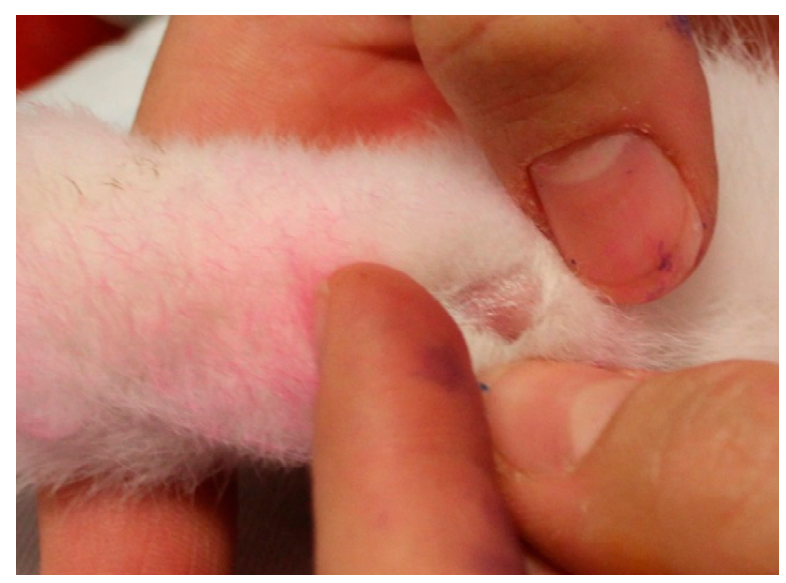

Figure 7. Hairless area at the hind feet found in all growing rabbits of this study at the middle (52 days of age) and end of the fattening period (77 days of age).

\subsection{Mortality Rates}

Mean mortality rates varied between F1, F2, and C housing (18.1 \pm 9 vs. $10.3 \pm 3$ vs. $11.7 \pm 6 \%$, respectively). However, no significant differences in the mortality rates were detected between the housing systems $(p>0.05$, Figure 8$)$. Nevertheless, the mortality rates tended to be higher in F1 compared to $\mathrm{F} 2$ and $\mathrm{C}$.

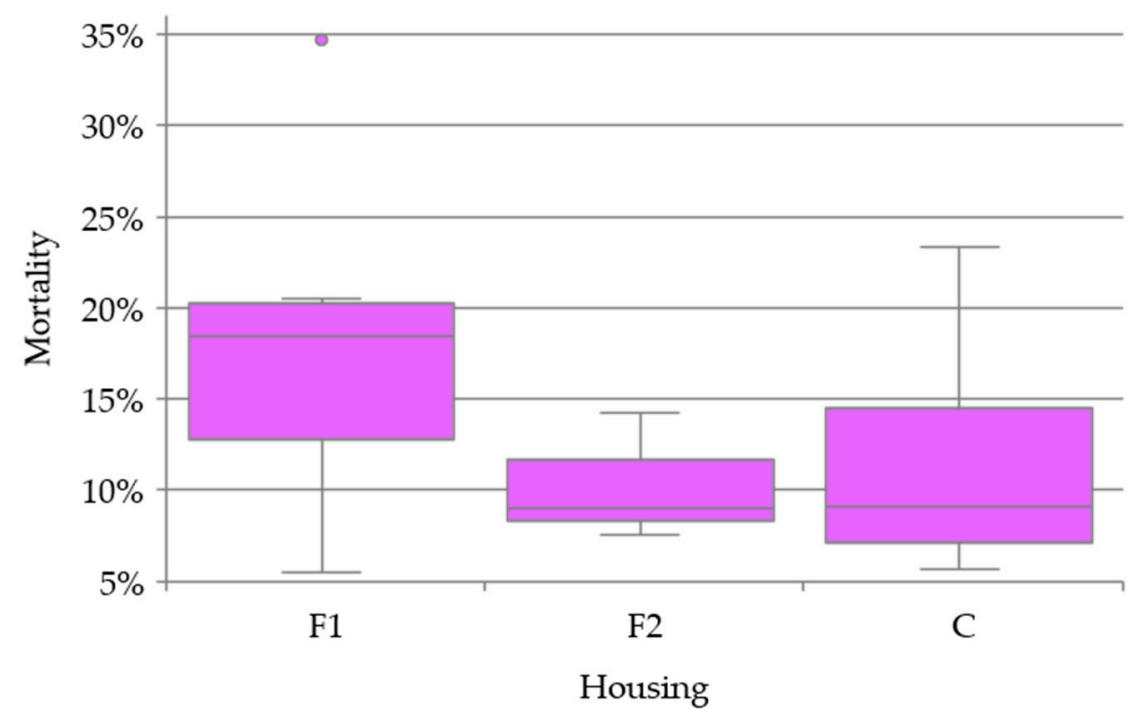

Figure 8. Mortality rates (\%) of rabbits per batch from weaning to slaughter in F1, F2, and C housing.

\section{Discussion}

While evaluating housing systems for fattening rabbits, the assessment of adequate flooring plays an important role, as animals rest and move on it during the entire housing period [4]. Alongside comfortability, maintaining sufficient hygienic conditions is vital $[3,9,16]$. Taking these aspects into account, many alternative flooring designs are less suitable for commercial rabbit husbandry. Therefore, wire mesh flooring is still recommended, especially for growing rabbits [3]. However, legal requirements 
have changed in different countries; cage systems with wire mesh flooring having been banned. Hence, the development of new flooring in accordance with current regulations has become necessary.

Previous studies already showed negative effects on animal soiling and health in practice when implementing the German regulations for flooring conditions $[18,21,22]$. However, our study results revealed that the effects on soiling strongly depend on the manner in which the legal requirements were implemented. This was also observed in a previous study investigating two different versions of perforated plastic floors, which both met Austrian legal requirements but differed in their perforation shape (slats vs. holes) [19]. Here, one was assessed as being less suitable in practice than the other. One of the main influencing factors for the severity of soiling of any one flooring type seems to be the degree of perforation $[18,19]$. As the degree of perforation is required by the German Animal Welfare Act, the present study deals with two versions of flooring with the same degree of perforation, but with a difference in surface structure and form. Soiling of floor space and elevated platforms was analyzed separately in pens in accordance with the German legislation and in cages of the established cage system on the same farm.

The assessment of floor space is especially important, as this area proportionally provides the largest area and was expected to show the highest level of use intensity. In this regard, F2 flooring was evaluated as being cleaner than F1 flooring. This may be due to its rounded surface, which allows fluids to be drained better, dries faster [18], and may impede the accumulation of manure. However, behavioral analyses should be carried out to ensure that the rounded surface does not hinder the rabbits' movement, even if this was not observed during the present investigation. Nevertheless, F2 flooring did not achieve the cleanliness of the wire mesh floor of the investigated cage system, although the latter was also assessed as score 3 in some cases. The main reason for score 3 being given in C housing was fur wrapped around the wire, which absorbed moisture and caused a wet surface. Overall, in this study, wire mesh flooring was again the cleanest option in comparison with the other floor types, as previously described [3,4]. However, investigations collecting data on the degree of soiling of wire mesh floors in comparison to alternative floor types are rare. One study on rabbit does did compare wire mesh flooring with other types in this regard, finding two alternative types of synthetic flooring to be as clean as wire mesh flooring [9]. However, these types of flooring did not meet the German legal requirements as requested for the present study.

Results also showed a severe soiling of the elevated platform at both observation days in F1 housing and at the end of the fattening period in F2 housing. The elevated platform is required by German legislation to have a maximum degree of perforation of $15 \%$. In the present study, both used elevated platforms meeting these requirements showed inadequate results for soiling. This was also shown in previous studies using $15 \%$ perforation [22] and 10\% perforation [18], both meeting the legal requirements. In F1, soiling was expected due to the dimensions of the non-perforated area. However, the distribution of solid flooring over the whole platform, with a more perforated area within this (F2), reduced the degree of soiling only in the middle of the fattening period. At this point, performing behavioral analyses would be beneficial to investigate the intensity of use of the elevated platforms to evaluate the relationship between the number of visiting rabbits and soiling. Thus, the less severe soiling of F2 platforms at day 52 may be due to lower usage. However, the larger distances between the solid flooring areas may also have a positive effect on manure accumulation, as score 2 was found less often for F2 platforms. Finally, C housing again showed the lowest degree of soiling, mostly being assessed as score 0 for the platform. This confirms a positive impact of the higher degree of perforation of $C$ platforms, which is equivalent to $45 \%$ perforation. The form and degree of perforation of this slatted plastic floor seems promising in terms of cleanliness and comfort, due to the square-shaped holes and the smooth plastic, which is important for preventing foot pad lesions [9]. This type of floor might be useful as floor space flooring as well, but would again not comply with German requirements. Nevertheless, when using highly perforated platforms, it has to be considered that droppings and urine may fall onto other rabbits under the platform [27]. However, no rabbits were observed as being noticeably soiled from above during the present investigations in $C$ housing. Due to the restricted space 
allowance and the high stocking density in C housing, a high intensity of use of the platforms was expected there, and was also observed during the investigations. Thus, the cleanliness of $C$ platforms is not predicted to be due to low usage.

Rabbits' hind feet reflected the results concerning the degree of soiling, with $C$ rabbits being the cleanest and F1 the most soiled rabbits. F2 rabbits showed better results than F1 rabbits, however they did not reach the cleanliness of $\mathrm{C}$ rabbits. $\mathrm{F} 1$ rabbits also showed an increase in soiling during housing, with more feet assessed as wet soiled (score 3) at day 77. One reason may be the increase in soiling of the platforms at day 77. As the soiling of floor space was similar at days 52 and 77, another assumption is that the rabbits were forced to use more of the available area with increasing age, in turn taking up more space, and thus they were also forced to use the wet places in the pen. In contrast, in C housing a decrease in soiling of hind feet was observed from day 52 until day 77, with more feet assessed as score 0 , but also a slight increase in the percentage of score 3 was found. The same tendency was also seen in floor soiling of $C$ housing, but without a significant effect. Wet areas due to wet fur wrapped around wire may increase with increasing time of housing. On the other hand, droppings, which may cause dry soiled areas, may more easily pass through the wire mesh at the end of the fattening period due to a greater size and weight of the animals pressing down the droppings. In this case, the wire mesh floor may prevent the animals from getting contaminated by their own droppings.

Soiling of the floor space, elevated platforms, as well as hind feet of rabbits differed between F1, $\mathrm{F} 2$, and $\mathrm{C}$ housing. In all cases, the modification of floor design of the new housing system showed an improvement, as F2 housing was assessed as being cleaner than F1. Nevertheless, the former still did not reach the cleanliness of $C$ housing. Intermediate cleaning, which was not usually conducted on this farm in the established cage system, would be recommended in the event of implementing F1 or F2 housing. However, this would not just mean a higher workload for the farmers, but is additionally questionable regarding its efficiency, especially in the case of the present platforms. On solid floors, for example, other authors also found wet areas, even if these were cleaned daily [5].

In contrast to other investigations [18,28], no footpad lesions (pododermatitis) were observed in rabbits in F1, F2, or C housing. Only small hairless spots at the hind area of the feet were observed in all rabbits. This agrees with the assumption that growing rabbits do not have any problems with pododermatitis due to their early slaughter age [3]. However, it cannot be ruled out that lesions at the feet may occur in the case of a longer housing period, not only in $\mathrm{C}$ housing due to the wire mesh floor [9], but also in F1 housing due to the severe soiling [17,18]. Due to the fact that rabbits' hind feet were less soiled in F2 than in F1 housing and that the flooring was smoother than in C housing, it remains to be seen whether F2 housing would show better results concerning footpad lesions in rabbits kept for a longer period.

Mortality rates were high, especially in F1 housing. Animals in F2 housing reached the mortality rates in $\mathrm{C}$ housing. A relationship between mortality rates and the degree of soiling was already observed in previous studies $[19,29]$ and is expected as rabbits are more likely to come in contact with excreta and pathogens. This was confirmed in the present results, as the housing system with the highest degree of soiling had the highest mortality rate. No significant differences in the mortality rates were detected between the housing systems, probably due to the sample size and the high standard deviation. Since only the number of surviving animals was counted, no further investigations into the causes of death were made. However, diarrhea was observed in some groups, which may have led to an increase in mortality rates.

Overall, F1 and F2 housing both differed in various factors regarding housing and management conditions to $\mathrm{C}$ housing, which may impede comparability. Thus, group size and stocking density differed, which may affect mortality rates $[13,30]$ and soiling. One particular influencing factor on soiling may be the difference in the duration of the housing period. Thus, $\mathrm{C}$ rabbits were kept for a shorter period in the system, since rabbits were moved to the cages after weaning, while F1 and F2 rabbits were born in the new system, without intermediate cleaning during the entire housing period. Nevertheless, the collected data should demonstrate how the different versions of the new housing 
system in accordance with the German legislation differed as a whole from an already established cage system. Such comparisons are necessary because amendments to the German welfare regulations will lead to profound changes in housing and management compared to previously established cages. Therefore, no single factor of a housing system was investigated, but a new complete housing and management system was compared to the former common system.

Even if the highest level of cleanliness was observed in C housing, the established cage system may cause other welfare issues [31-33] (e.g., spatial restriction and high stocking densities), and it should not be used again. In this regard, F2 and F1 housing are expected to provide some benefits, providing more space per animal and an increased total ground area for movement [34-36]. In addition, they offer increased environmental enrichment and more structural elements, which may have a positive impact on the behavior and performance of fattening rabbits [36,37]. Thus, with an improvement in the hygienic situation, the new housing system could be promising in terms of animal welfare.

A major issue is that there are no housing systems and flooring types available on the market that allow rabbits to be kept in compliance with the German regulations and in good health, even if the German regulations have to be implemented on farms from 2019 onwards. There are only a few pilot systems, and the investigations on these have assessed them as not being suitable for commercial rabbit husbandry due to hygienic problems [18,21]. This study showed an improvement in the hygienic conditions resulting from a modification in the flooring. Nevertheless, the modified system still did not reach the cleanliness of the established system that utilizes wire mesh floors. In the end, the perfect floor meeting all German legal requirements and rabbits' needs is still missing, although more perforated ones seem to be beneficial in terms of soiling and animal health. The German regulations concerning the $15 \%$ perforation of the elevated platform seem questionable, as this aspect was hygienically inadequate in both studied versions, and also in earlier studies [18,22]. On the contrary, some types of floors were found to comply with one aspect stipulated in the German legal requirements $(10 \mathrm{~mm}$ slats, $10 \mathrm{~mm}$ gaps), however not considering the $15 \%$ regulation, in fact showed no negative effects and were assessed as being suitable in practice $[19,38]$. Considering that the housing systems are difficult to compare because of various influencing factors, further research on flooring design for fattening rabbits is encouraged. Nevertheless, even if it was possible to find an adequate housing system complying with the legal restrictions, time is running out for German farmers to implement such a system on their farms. Furthermore, it remains disputable whether it is economically feasible in practice. These aspects should be considered from a political point of view before insisting on the implementation of entirely new regulations on farms.

Author Contributions: Conceptualization, S.L.R. and M.F.; methodology, S.L.R., J.B., and M.F., validation, S.L.R. and M.F.; formal analysis, S.L.R. and M.F.; investigation, S.L.R., J.B., and S.K.; resources, N.K.; data curation, S.L.R. and S.K.; writing—original draft preparation, S.L.R.; writing-review and editing, S.L.R., J.B., N.K., and M.F.; visualization, S.L.R. and J.B.; supervision, N.K. and M.F.; project administration, S.L.R. and M.F.; funding acquisition, N.K. and M.F.

Funding: This study was funded by the agricultural European Innovation Partnership (EIP-AGRI) in a framework of the project "Rawecoh-Le".

Acknowledgments: The authors wish to thank the participating farm staff and colleagues for their assistance. Special thanks go to Isabel Sowka, Harald Ulbrich, and Kai Göbel for their support during data collection.

Conflicts of Interest: The authors declare no conflict of interest. The funders had no role in the design of the study; in the collection, analyses, or interpretation of data; in the writing of the manuscript, or in the decision to publish the results.

\section{References}

1. DG Health and Food Safety. Commercial Rabbit Farming in the European Union; Publications Office of the European Union: Brussels, Luxembourg, 2018. [CrossRef]

2. Gerencsér, Z.; Szendrő, K.; Szendrő, Z.; Odermatt, M.; Radnai, I.; Nagy, I.; Dal Bosco, A.; Matics, Z. Effect of floor type on behavior and productive performance of growing rabbits. Livest. Sci. 2014, 165, 114-119. [CrossRef] 
3. Morton, D.; Verga, M.; Blasco, A.; Cavani, C.; Gavazza, A.; Maertens, L.; Mirabito, L.; Rosell, J.M.; Stauffacher, M.; Szendrò, Z. The Impact of the current housing and husbandry systems on the health and welfare of farmed domestic rabbits. EFSA 2005, 267.

4. Szendrő, Z. New perspectives of housing reproducting and growing rabbits. In Proceedings of the 10th World Rabbit Congress, Sharm El-Sheikh, Egypt, 3-6 September 2012; pp. 979-996.

5. Matics, Z.; Szendrő, Z.; Radnai, I.; Biró-Németh, E.; Gyovai, M. Examination of free choice of rabbits among different cage-floors. Agric. Conspec. Sci. 2004, 68, 265-268.

6. Princz, Z.; Dalle Zotte, A.; Radnai, I.; Bíró-Németh, E.; Matics, Z.; Gerencsér, Z.; Nagy, I.; Szendrő, Z. Behaviour of growing rabbits under various housing conditions. Appl. Anim. Behav. Sci. 2008, 111, 342-356. [CrossRef]

7. Miko, A.; Matics, Z.; Gerencser, Z.; Odermatt, M.; Radnai, I.; Nagy, I.; Szendro, K.; Szendro, Z. Performance and welfare of rabbit does in various caging systems. Anim. Int. J. Anim. Biosci. 2014, 8, 1146-1152. [CrossRef] [PubMed]

8. Petersen, J.; Schlender-Böbbis, I.; Mennicken, L. Evaluation of optimal slat distance in slatted floor for rabbits using behavioural studies. In Proceedings of the 7th World Rabbit Congress, Valencia, Spain, 4-7 July 2000; pp. 559-565.

9. Rommers, J.M.; Meijerhof, R. The effect of different floor types on footpad injuries of rabbit does. In Proceedings of the 6th World Rabbit Congress, Toulouse, France, 9-12 July 1996.

10. Rosell, J.M.; de la Fuente, L.F. Assessing Ulcerative Pododermatitis of Breeding Rabbits. Anim. Open Access J. 2013, 3, 318-326. [CrossRef] [PubMed]

11. Morisse, J.P.; Boilletot, E.; Martrenchar, A. Preference testing in intensively kept meat production rabbits for straw on wire grid floor. Appl. Anim. Behav. Sci. 1999, 64, 71-80. [CrossRef]

12. Lambertini, L.; Vignola, G.; Zaghini, G. Alternative pen housing system for fattening rabbits: effects of group density and litter. World Rabbit Sci. 2001, 9, 141-147.

13. Dal Bosco, A.C.C.; Mugnai, C. Rearing rabbits on a wire net floor or straw litter: Behaviour, growth and meat qualitative traits. Livest. Prod. Sci. 2002, 75, 149-156. [CrossRef]

14. Fleischer, A. Ethologische Untersuchungen an Mastkaninchen zur Präferenz unterschiedlicher Bodenarten sowie Licht und Dunkelheit anhand von Wahlversuchen. Ph.D. Thesis, Universität Hohenheim, Hohenheim, Germany, 1998.

15. Orova, Z.; Szendro, Z.; Matics, Z.; Radnai, I.; Biró-Németh, E. Free choice of growing rabbits between deep litter and wire net floor in pens. In Proceedings of the 8th World Rabbit Congress, Puebla, Mexico, 7-10 September 2004; pp. 1263-1265.

16. Hoy, S.; Verga, M. Welfare Indicators; Maertens, L., Coudert, P., Eds.; Institute for Agricultural and Fisheries Research (ILVO): Melle-Belgium, Belgium, 2006; pp. 71-74.

17. Zegowitz, B.; Masthoff, T.; Lang, C. Results of choice tests regarding preference and suitability of different floor structures in rabbits. In Proceedings of the 20th Symposium on Housing and Diseases of Rabbits, Furbearing Animals and Pet Animals, Celle, Germany, 17-18 May 2017.

18. Masthoff, T.; Hoy, S. Investigations on the influence of floor design on dirtiness and foot pad lesions in growing rabbits. Animals 2019, 9, 354. [CrossRef] [PubMed]

19. Tillmann, K.; Windschnurer, I.; Gamper, J.; Hinney, B.; Rulicke, T.; Podesser, B.K.; Troxler, J.; Plasenzotti, R. Welfare assessment in rabbits raised for meat and laboratory purposes in enclosures with two floor types: Perforated plastic with holes versus slats. Res. Vet. Sci. 2019, 122, 200-209. [CrossRef] [PubMed]

20. TierSchNutztV. Anforderungen an das Halten von Kaninchen. In Fünfte Verordnung zur Änderung der Tierschutz-Nutztierhaltungsverordnung; Bonn, Germany, 2014; Available online: https://www.gesetze-iminternet.de/tierschnutztv/BJNR275800001.html (accessed on 7 November 2019).

21. Rauterberg, S.L.; Bill, J.; Kimm, S.; Kemper, N.; Fels, M. Effect of A New Housing System on Skin Lesions, Performance and Soiling of Fattening Rabbits: A German Case Study. Anim. Open Access J. 2019, 9, 650. [CrossRef] [PubMed]

22. Leinberger, L.; Bauer, T.; Hoy, S. Effects of a 15\% perforation of elevated floor on cleanliness and health of rabbits. In Proceedings of the 21th Symposium on Housing and Diseases of Rabbits, Furbearing Animals and Pet Animals, Hannover, Germany, 16-17 May 2019.

23. R Core Team. R: A language and Environment for Statistical Computing; R Foundation for Statistical Computing: Vienna, Austria, 2019; Available online: https://www.R-project.org/ (accessed on 7 November 2019). 
24. Venables, W.N.; Ripley, B.D. Modern Applied Statistics with S, 4th ed.; Springer: Berlin, Germany, 2002.

25. Zeileis, A.; Hothorn, T. Diagnostic Checking in regression relationships. $R$ News 2002, 2, 7-10.

26. Kleiber, C.; Zeileis, A. Applied Econometrics with R; Springer: Berlin, Germany, 2008.

27. Szendrő, Z.; Matics, Z.; Odermatt, M.; Gerencser, Z.; Nagy, I.; Szendro, K.; Dalle Zotte, A. Use of different areas of pen by growing rabbits depending on the elevated platforms' floor-type. Anim. Int. J. Anim. Biosci. 2012, 6, 650-655. [CrossRef] [PubMed]

28. Masthoff, T.; Lang, C.; Buhl, M.; Hoy, S. Influence of floor type on dirtness of floor and leg health in growing rabbits. In Proceedings of the 19th Symposium on Housing and Diseases of Rabbits, Furbearing Animals and Pet Animals, Celle, Germany, 27-28 May 2015.

29. Princz, Z.; Dalle Zotte, A.; Metzger, S.; Radnai, I.; Biró-Németh, E.; Orova, Z.; Szendrő, Z. Response of fattening rabbits reared under different housing conditions. 1 . Live performance and health status. Livest. Sci. 2009, 121, 86-91. [CrossRef]

30. Maertens, L.; Van Herck, A. Performances of weaned rabbits raised in pens or in classical cages: First results. In Proceedings of the 7th World Rabbit Congress, Valencia, Spain, 4-7 July 2000; pp. 435-440.

31. Drescher, B. Housing of rabbits with respect to animal welfare. In Proceedings of the 5th Congress of the World Rabbit Science Association, Corvallis, Oregon, 25-30 July 1992; pp. 678-683.

32. Schlolaut, W. Kaninchenhaltung: Richtiges management (II). DGS 1992, 48, 1404-1407.

33. Verga, M.; Luzi, F.; Carenzi, C. Effects of husbandry and management systems on physiology and behaviour of farmed and laboratory rabbits. Horm. Behav. 2007, 52, 122-129. [CrossRef] [PubMed]

34. Martrenchar, A.; Boilletot, E.; Corte, J.-P.; Morisse, J.-P. Wire-floor pens as an alternative to metallic cages in fattening rabbits: influence on some welfare traits. Anim. Welfare 2001, 10, 153-161.

35. Postollec, G.; Boilletot, E.; Maurice, R.; Michel, V. The effect of pen size and an enrichment structure (elevated platform) on the performances and the behaviour of fattening rabbits. Anim. Welfare 2008, 17, 53-59.

36. Kimm, S.; Rauterberg, S.L.; Bill, J.; Kemper, N.; Fels, M. Assessment of a new housing system in accordance with the TierSchNutztV with regard to behaviour and animal health of fattening rabbits. In Proceedings of the 21th Symposium on Housing and Diseases of Rabbits, Furbearing Animals and Pet Animals, Hannover, Germany, 16-17 May 2019; pp. 5-6.

37. Luzi, F.; Ferrante, V.; Heinzl, E.; Verga, M. Effect of environmental enrichment on productive performance and welfare aspects in fattening rabbits. Ital. J. Anim. Sci. 2003, 2, 438-440. [CrossRef]

38. Reiter, J. Untersuchungen zur Optimierung der Gruppengröße bei Mastkaninchen in Gruppenhaltung auf Kunststoffrosten. Ph.D. Thesis, University of Stuttgart/Hohenheim, Hohenheim, Germany, 1995. 